\title{
BRONCHIOLOALVEOLAR CARCINOMA
}

$S_{b}^{\text {in }}$

ince its first description by Malassez ${ }^{1}$ in 1876 , bronchioloalveolar carcinoma (BAC) has been considered a multicentric tumor with a dismal prognosis. ${ }^{2}$ Later studies, however, demonstrated that

From the Division of Thoracic Surgery, Department of Surgery, Taichung Veterans General Hospital, Taichung, Taiwan, Republic of China.

Received for publication Sept. 15, 1994.

Accepted for publication Nov. 28, 1994.

Address for reprints: Chung-Ping Hsu, MD, Division of Thoracic Surgery, Department of Surgery, Taichung Veterans General Hospital, \#160, Sec 3, Taichung-Kang Rd., Taichung, Taiwan, Republic of China.
Bronchioloalveolar carcinoma is a subtype of adenocarcinoma of the lung with a relatively better prognosis. We reviewed the cases of $\mathbf{5 0}$ consecutive patients with bronchioloalveolar carcinoma treated during a 10-year period and attempted to analyze factors related to prognosis. During the 10-year study period, the prevalence of bronchioloalveolar carcinoma relative to adenocarcinoma of the lung remained steady. The subjects included 32 male and 18 female patients with mean ages of 64.7 years and 55.1 years, respectively $(p=0.0030)$. The preoperative radiographic findings included 40 cases of localized and 10 cases of diffuse bronchioloalveolar carcinoma. The clinicopathologic TNM staging included 20 patients with stage I cancer, 4 with stage II cancer, 11 with stage IIIa cancer, 3 with stage IIIb cancer, and 12 with stage IV cancer. Forty patients with clinical stage I, II, or III disease underwent operation (operability $80 \%$ ). The resectability rate was $90 \%$ ( 36 of 40 ). Thirty-four procedures were considered as curative. The overall cumulative survival at 5 years was $22.2 \%(46.4 \%$ for stage I). Different TNM stages showed significant differences in survival time $(p=$ 0.0001). The median survival times were 64.6 months for stage I, 48.0 months for stage II, 24.7 months for stage IIIa, 9.0 months for stage IIIb, and 4.5 months for stage IV disease. The median survival time for localized bronchioloalveolar carcinoma was 27.5 months, and the median survival time for diffuse bronchioloalveolar carcinoma was 4.3 months $(p=0.0002)$. The median survival time for the curative resection group was 30.6 months, and the median survival time for the noncurative resection or nonresection group was 5.8 months $(p=0.0001)$. On the basis of this study we conclude that (1) the prevalence of bronchioloalveolar carcinoma is quite steady, (2) bronchioloalveolar carcinoma presents at an earlier age in women, (3) bronchioloalveolar carcinoma frequently presents with lymphatic spread or systemic metastasis at diagnosis, (4) most localized bronchioloalveolar carcinomas are resectable and the prognosis with this type is better than that of the diffuse type, and (5) long-term survival correlates closely with initial roentgenographic appearance, TNM stage, and completeness of surgical resection. (J THORAC CARDIOVASC SURG 1995;110:374-81)

Chung-Ping Hsu, MD, Chih-Yi Chen, MD, and Nan-Yung Hsu, MD, Taichung, Taiwan, Republic of China most BACs occur as solitary pulmonary nodules. ${ }^{3-5}$ This has been further supported by recent reports. ${ }^{6,7}$ Although numerous labels were attached to this tumor of uncertain origin, Leibow ${ }^{8}$ in 1960 was the first to describe the frequent association with the small peripheral airways and alveolar spaces and introduced the term bronchioloalveolar carcinoma. The multiple faces of BAC have been well described. ${ }^{9}$ BAC, which presents as multiple foci pulmonary infiltrates, is frequently of the mu-

Copyright (C) 1995 by Mosby-Year Book, Inc.

$0022-5223 / 95 \$ 3.00+0 \quad \mathbf{1 2 / 1 / 6 2 4 6 4}$ 
cin-secreting type, which bears a much worse prognosis than the nodular type. ${ }^{10}$

Characteristically, BAC advances by local invasion along the alveolar wall or undergoes aerogenous spread. The roentgenologic presentation may be expressed as a single pulmonary nodule, multiple pulmonary nodules, localized infiltrates, or even multiple foci infiltrates at different lobes. The latter pattern may be either synchronous or metachronous. Metastasis commonly involves both hematogenous and lymphatic routes. 8,11

We reviewed our experience with 50 consecutive patients with BAC treated during a 10-year period. The prevalence of $\mathrm{BAC}$ relative to adenocarcinoma of the lung was studied. In addition, the relationships between radiographic findings at diagnosis, completeness of resection, tumor staging, and prognosis were investigated to obtain determinants of survival in patients with BAC.

\section{Patients and methods}

Between January 1, 1983, and December 31, 1992, 1205 patients with adenocarcinoma of the lung were admitted to Taichung Veterans General Hospital. Fifty consecutive cases of BAC were identified and the patients enrolled in this study. There were 32 male and 18 female patients. The mean age at diagnosis for male and female patients was 64.7 years and 55.1 years, respectively. The demographic data of these patients are shown in Table $I$.

The prevalence of BAC in relationship to adenocarcinoma of the lung was calculated for each individual year.

The preoperative work-ups included plain chest film, fiberbronchoscopy, chest computed tomographic (CT) scan, liver sonography, whole body bone scan, and pulmonary function test to evaluate the possible effectiveness of surgical therapy. To simplify the clinical classification, we divided the roentgenographic patterns of BAC into "localized" and "diffuse" types. A solitary pulmonary nodule or mass was classified as localized BAC. An infiltrative type or multiple foci tumor was classified as diffuse BAC. Pathologic diagnosis of pulmonary malignancies was obtained in all patients. Cases with the focal area of BAC in adenocarcinoma of the lung were not unusual, and patients with this finding were excluded from this study.

The methods of diagnosis included pneumonectomy (3), bilobectomy (2), lobectomy (20), wedge resection (11), open lung biopsy (4), needle lung biopsy (6), and cytology (4). Forty patients, with clinical stages ranging from I to IIIa, underwent thoracotomy, and 36 pulmonary resections were done. All of the patients who receive operation also underwent mediastinal lymph node dissection or sampling for nodal staging. A curative resection was defined when no gross or microscopic residual tumor remained. All of the current survivors have been followed up for more than 20 months.

The survival analysis by the Kaplan-Meier method ${ }^{12}$ and data comparison by the Lee-Desu statistical method ${ }^{13}$
Table I. Demographic data of 50 BAC cases

\begin{tabular}{|c|c|}
\hline Characteristics & No. of patients \\
\hline \multicolumn{2}{|l|}{ Sex of patient } \\
\hline Male & 32 \\
\hline Female & 18 \\
\hline \multicolumn{2}{|l|}{$\mathrm{X}$-ray findings } \\
\hline Mass & 40 \\
\hline Infiltrative & 10 \\
\hline \multicolumn{2}{|l|}{ Location } \\
\hline RUL & 8 \\
\hline RML & 4 \\
\hline RLL & 5 \\
\hline LUL & 12 \\
\hline LLL & 8 \\
\hline Multiple unilateral & 4 \\
\hline Multiple bilateral & 9 \\
\hline \multicolumn{2}{|l|}{ Diagnostic method } \\
\hline Lobectomy & 20 \\
\hline Bilobectomy & 2 \\
\hline Pneumonectomy & 3 \\
\hline Wedge resection & 11 \\
\hline Open lung biopsy & 4 \\
\hline Needle biopsy & 6 \\
\hline Cytology & 4 \\
\hline \multicolumn{2}{|l|}{ Curative resection } \\
\hline Yes & 34 \\
\hline No & 16 \\
\hline \multicolumn{2}{|l|}{ Stage } \\
\hline I & 20 \\
\hline II & 4 \\
\hline IIIa & 11 \\
\hline $\mathrm{IIIb}$ & 3 \\
\hline IV & 12 \\
\hline Total & 50 \\
\hline
\end{tabular}

$R U L$, Right upper lobe; $R M L$, right middle lobe; $R L L$, right lower lobe; $L U L$, left upper lobe; $L L L$, left lower lobe.

were done with the use of the SPSS/PC ${ }^{+}$Advanced Statistic 4.0 software package for microcomputer data management and analysis (SPSS Inc., Chicago, Ill.).

\section{Results}

Distribution of BAC. During the 10-year period, 50 cases of BAC, among 1205 cases of adenocarcinoma of the lung, were encountered: a prevalence of $4.1 \%$. The annual occurrences of BAC ranged from 1 to $8(1.4 \%$ to $7.6 \%$ of overall adenocarcinoma of lung). The relationship between BAC and adenocarcinoma is shown in Fig. 1. The prevalence of BAC during the most recent 4 years remained steady in the range of $4.1 \%$ to $4.6 \%$.

Gender and ages. There were 32 male and 18 female patients. Their ages ranged from 22 to 76 years. The mean age of male and female patients was 64.7 years (SD*9.6) and 55.1 years (SD 10.5),

${ }^{*}$ Standard deviation. 


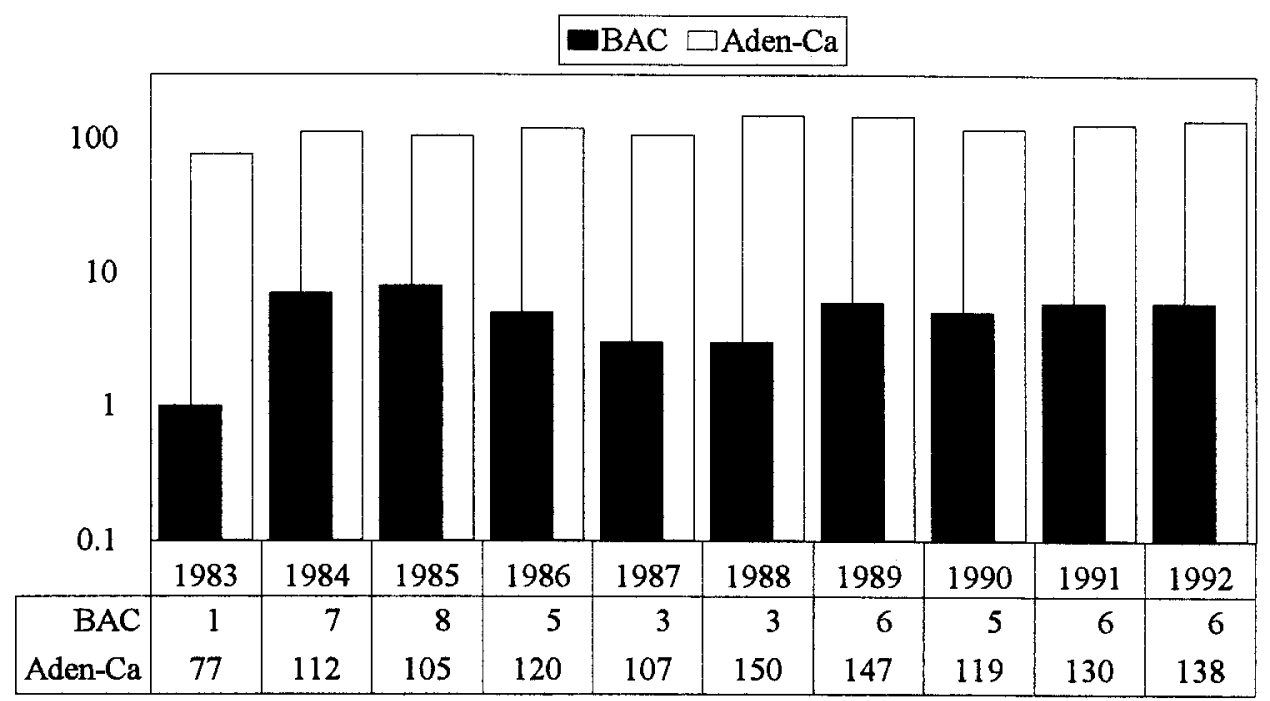

Fig. 1. Annual occurrence of $\mathrm{BAC}$ in relationship to adenocarcinoma (Aden-Ca) of lung during 10-year period.

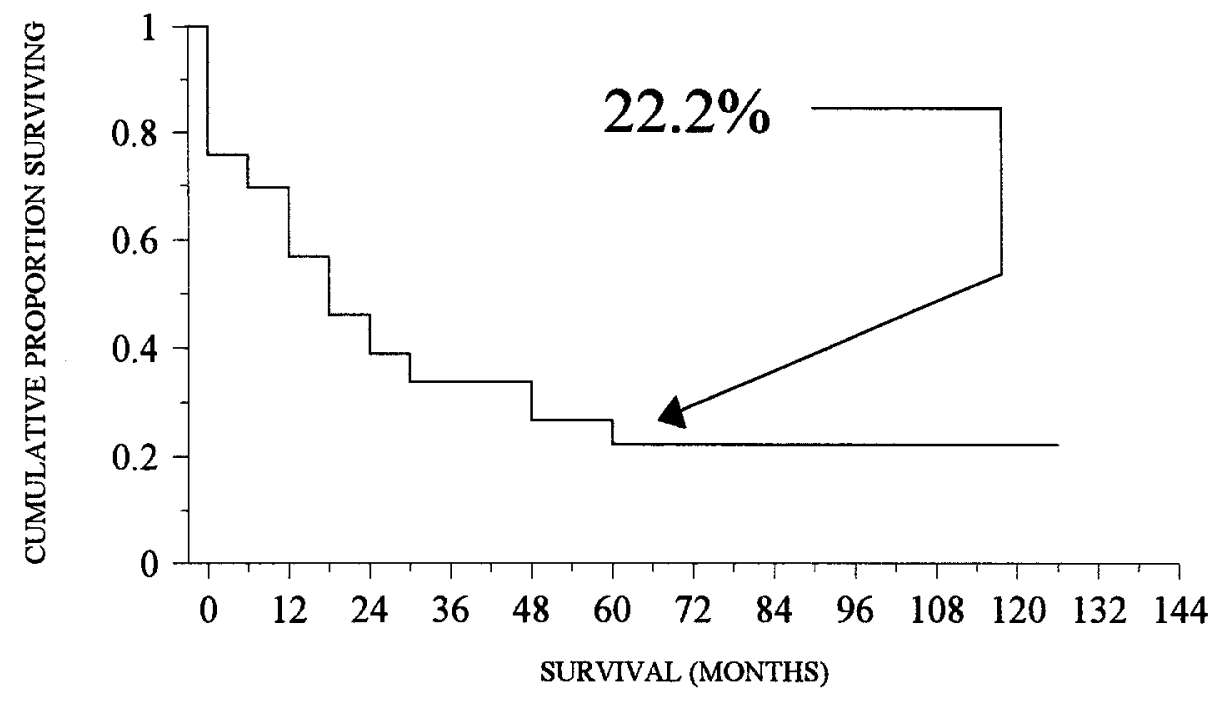

\begin{tabular}{|c|c|c|c|c|c|c|c|}
\cline { 2 - 7 } \multicolumn{1}{c|}{} & follow-up & 0 & ly & $2 y$ & $3 y$ & $4 y$ & $5 y$ \\
\hline pt. at risk & Total & 50 & 33 & 20 & 12 & 10 & 6 \\
\hline SE & Total & 0.061 & 0.071 & 0.072 & 0.071 & 0.072 & 0.072 \\
\hline
\end{tabular}

Fig. 2. Overall cumulative survival curve in 50 cases of BAC with 5-year survival of $22.2 \%$. pt., Patients; $S E$, standard error.

respectively. Our data showed that the women were younger than the men at the time of diagnosis $(p=$ 0.0030 ).

TNM stage. The clinicopathologic TNM staging of the disease included 20 patients with stage I disease, 4 stage II, 11 stage IIIa, 3 stage IIIb, and 12 stage IV. The overall cumulative survival curve is shown in Fig. 2. The 5-year survival was $22.2 \%$. The median survival times were 64.6 months for stage I, 48.0 months for stage II, 24.7 months for stage IIIa, 9.0 months for stage IIIb, and 4.5 months for stage IV. Fig. 3 shows the cumulative survival curves for different stages of BAC $(p=0.0001)$. The $p$ values for the differences in survival times among the different stages are listed in Table II. Our data clearly demonstrated a better prognosis for stages I, 


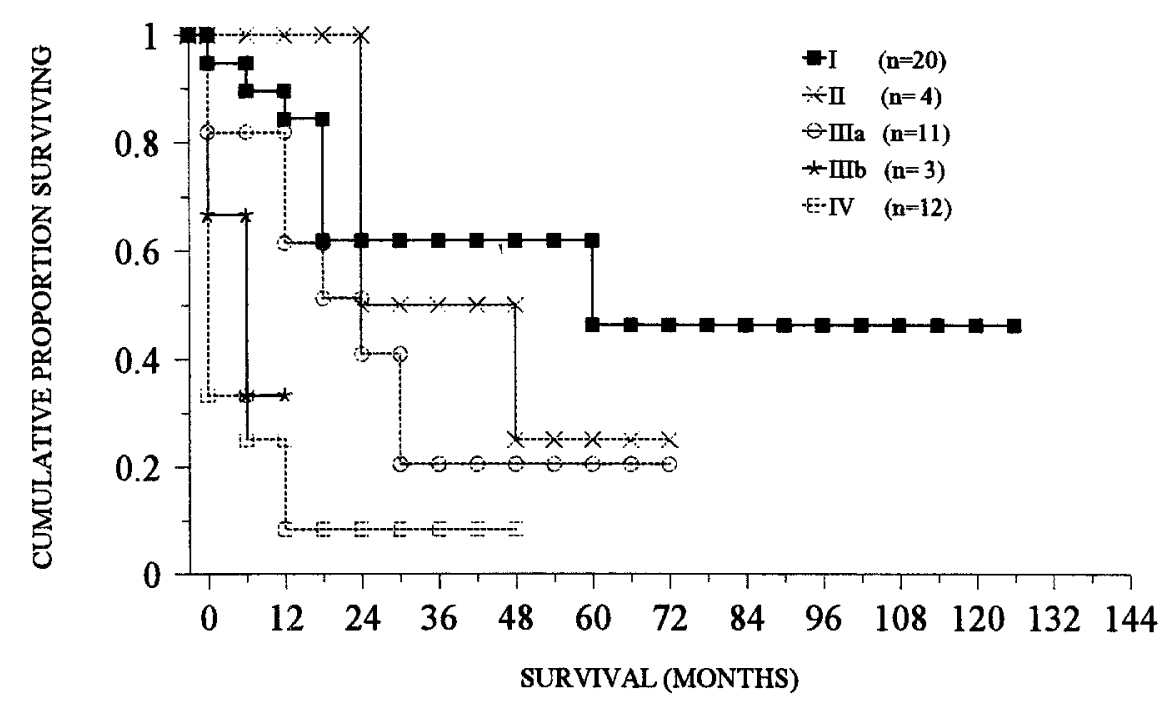

\begin{tabular}{|c|c|c|c|c|c|c|c|}
\hline \multirow{4}{*}{ pt. at risk } & follow-up & 0 & ly & $2 y$ & $3 y$ & $4 y$ & $5 y$ \\
\cline { 2 - 8 } & I & 20 & 17 & 10 & 7 & 5 & 4 \\
\cline { 2 - 8 } & II & 4 & 4 & 4 & 2 & 2 & 1 \\
\cline { 2 - 8 } & IIIa & 11 & 8 & 5 & 2 & 2 & 1 \\
\cline { 2 - 8 } & IIIb & 3 & 1 & - & - & - & - \\
\hline IV & 12 & 3 & 1 & 1 & 1 & - \\
\hline & I & 0.050 & 0.083 & 0.114 & 0.114 & 0.114 & 0.159 \\
\cline { 2 - 9 } & II & 0 & 0 & 0.250 & 0.250 & 0.217 & 0.217 \\
\cline { 2 - 8 } & IIIa & 0.116 & 0.153 & 0.156 & 0.129 & 0.129 & 0.129 \\
\cline { 2 - 8 } & IIIb & 0.272 & 0 & - & - & - & - \\
\cline { 2 - 8 } & IV & 0.136 & 0.080 & 0.080 & 0.080 & 0 & - \\
\hline
\end{tabular}

Fig. 3. Cumulative survival curves among different stages of BAC $(p=0.0001)$. pt., Patients; $S E$, standard error.

II, and IIIa BAC than for stage IV BAC. Comparison of the survival times for T1 N0 M0 and T2 N0 M0 BAC is shown in Fig. 4. T1 lesions tended to show a better outcome than T2 lesions $(p=0.0961)$. The current status of the patients, according to different stages, is listed in Table III. During the study period 34 patients died, 4 patients were lost to follow-up, and 12 patients survived.

Roentgenographic patterns. The preoperative roentgenographic presentations included $40(80 \%)$ cases of localized BAC (mass/nodular lesions) and $10(20 \%)$ of diffuse BAC (multiple nodules or infiltrative lesions). The former group had a resection rate of $82.5 \%$, and the latter group had a resection rate of $30 \%$. The median survival time was 27.5 months for localized BAC and 4.3 months for diffuse BAC. Fig. 5 shows the cumulative survival curves according to the roentgenologic presentations $(p=0.0002)$.

Pulmonary resection. Ten patients in this study did not receive thoracotomy. Two of these were patients with stage I lung cancer who did not consent to surgical treatment. The other eight patients were
Table II. $p$ Values for different stages of $B A C$

\begin{tabular}{ccccc}
\hline & \multicolumn{4}{c}{ Stage } \\
\cline { 2 - 5 } & II & IIIa & IIIb & $I V$ \\
\hline Stage & & & & \\
I & 0.8062 & 0.1653 & 0.0075 & 0.0001 \\
II & - & 0.2583 & 0.0339 & 0.0109 \\
IIIa & - & - & 0.0559 & 0.0035 \\
IIItb & - & - & - & 0.5637 \\
\hline
\end{tabular}

not operated on because of distant metastasis. Forty patients with clinical stage I to IIIa lung cancer received exploratory thoracotomy. Thirty-six tumors were resected, and 34 of the procedures were considered as curative. Two patients with stage IIIb disease who received surgical resection were categorized into the noncurative resection group because of gross residual tumor. The median survival time was 30.6 months for the curative resection group and 5.8 months for the noncurative resection or nonresection group. Fig. 6 shows the cumulative survival curves according to the type of resection $(p=0.0001)$. The distribution of resection types for the different stages 


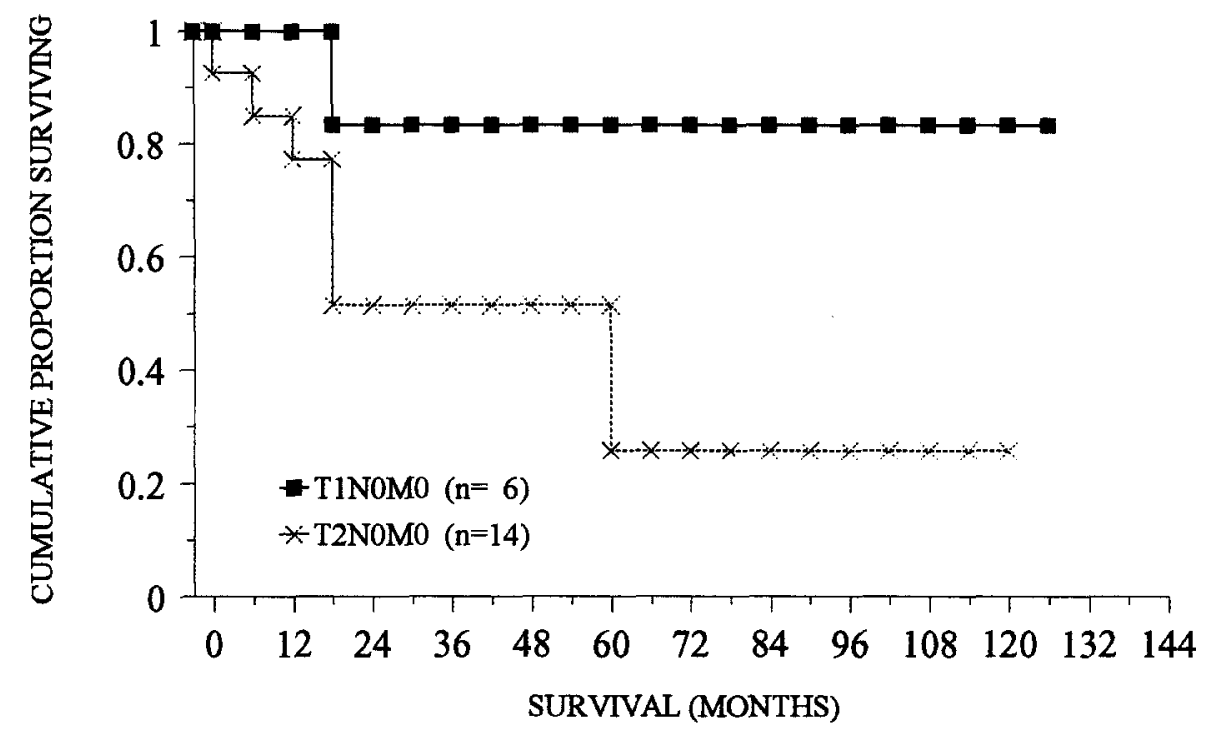

\begin{tabular}{|c|c|c|c|c|c|c|c|}
\cline { 2 - 7 } \multicolumn{1}{c|}{} & follow-up & 0 & $1 \mathrm{y}$ & $2 \mathrm{y}$ & $3 \mathrm{y}$ & $4 \mathrm{y}$ & $5 \mathrm{y}$ \\
\hline \multirow{3}{*}{ pt. at risk } & TINOMO & 6 & 6 & 5 & 4 & 3 & 2 \\
\cline { 2 - 8 } & T2NOM0 & 14 & 11 & 5 & 3 & 2 & 2 \\
\hline \multirow{2}{*}{ SE } & TINOMO & 0 & 0 & 0.152 & 0.152 & 0.152 & 0.152 \\
\cline { 2 - 8 } & T2NOMO & 0.071 & 0.116 & 0.144 & 0.144 & 0.144 & 0.196 \\
\hline
\end{tabular}

Fig. 4. Cumulative survival curves of cases of T1 N0 M0 and T2 N0 M0 BAC $(p=0.0961)$. pt., Patients; $S E$, standard error.

Table III. Current status of patients according to different stages

\begin{tabular}{lcccc}
\hline & \multicolumn{4}{c}{ Status } \\
\cline { 2 - 4 } Stage & Dead & Alive & $\begin{array}{c}\text { Lost to } \\
\text { follow-up }\end{array}$ & Total \\
\hline I & 8 & 9 & 3 & 20 \\
II & 3 & 0 & 1 & 4 \\
IIIa & 8 & 3 & 0 & 11 \\
IIIb & 3 & 0 & 0 & 3 \\
IV & 12 & 0 & 0 & 12 \\
Total & 34 & 12 & 4 & 50 \\
\hline
\end{tabular}

of BAC is shown in Table IV. The $p$ values for the difference in survival times among the different stages, after curative resection, are listed in Table V.

\section{Discussion}

BAC is a subtype of adenocarcinoma of the lung. It accounts for $1 \%$ to $9 \%$ of the total pulmonary malignancies. $4,6,14,15$ The cause of $\mathrm{BAC}$ is still unclear. Unlike small-cell and squamous cell carcinomas of the lung, there is no definite link between BAC and smoking. ${ }^{7}$ The pathologic architecture of BAC is similar to that of jaagsiekte disease in sheep ${ }^{16-18}$; however, only sporadic studies have sug- gested that $\mathrm{BAC}$ in human beings is related to the virus. ${ }^{19,20}$ The cell origin may be either the type II pneumocyte (nonmucinous) or the Clara cell. ${ }^{21-24} \mathrm{~A}$ familial recessive trait in $\mathrm{BAC}$ has been reported; however, this is unusual. ${ }^{25}$

Noninvasive procedures for diagnosis of $\mathrm{BAC}$ are unreliable. Roentgenographically, BAC is a great mimicker. It can present as a solitary pulmonary mass or nodule, focal pulmonary infiltrates, or multiple foci pulmonary infiltrates. $8,9,15$ One study demonstrated that CT scan findings such as a starlike pattern, pseudocavitation, heterogeneous attenuation, pleural tags, and air bronchogram are characteristic of BAC. ${ }^{26}$ Most of our patients had a preoperative chest CT scan; however, all of the aforementioned clues for the diagnosis of $\mathrm{BAC}$ were incidental findings.

One study demonstrated that BAC makes up an unusually high percentage $(23.5 \%)^{27}$ of total primary bronchogenic adenocarcinoma. However, more often BAC comprises only a small portion of the primary lung cancers. The overall proportion of BAC in bronchogenic adenocarcinoma in this institute was $4.9 \%$, which is consistent with that of other series. Moreover, this ratio was relatively constant during the most recent 4 years (ranging from $4.1 \%$ 


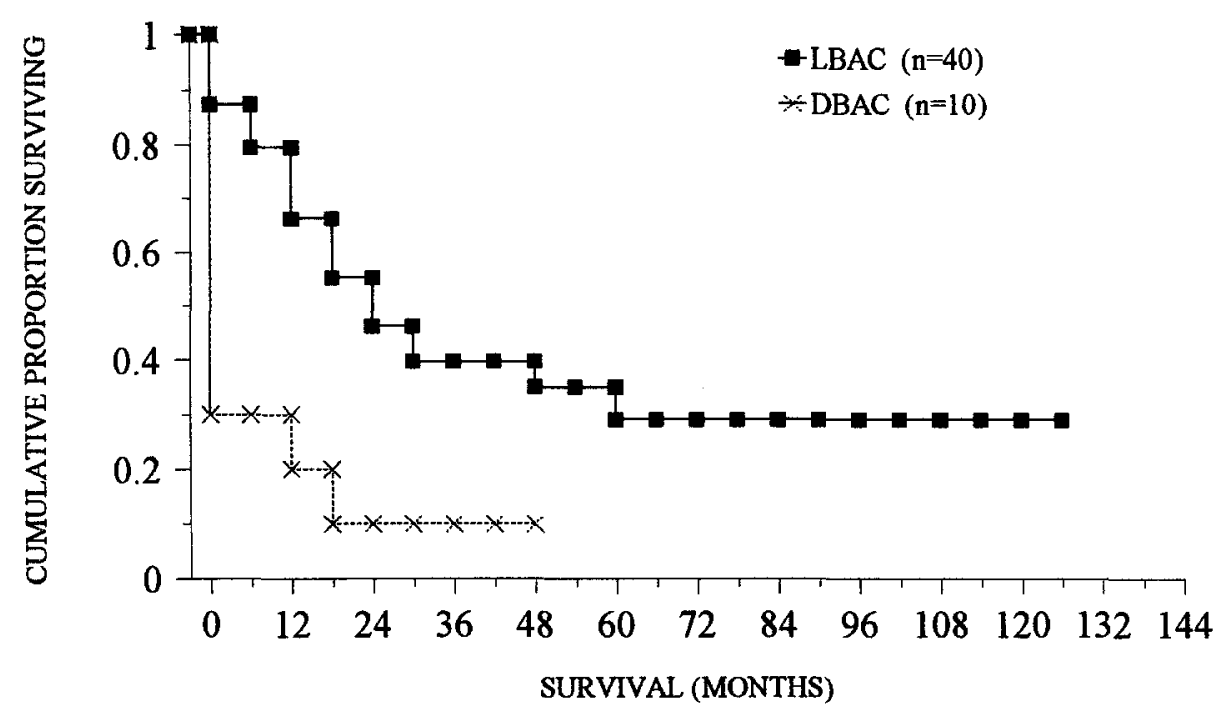

\begin{tabular}{|c|c|c|c|c|c|c|c|}
\cline { 2 - 8 } \multicolumn{1}{c|}{} & follow-up & 0 & $1 y$ & $2 y$ & $3 y$ & $4 y$ & $5 y$ \\
\hline \multirow{3}{*}{ pt. at risk } & LBAC & 40 & 30 & 19 & 11 & 9 & 6 \\
\cline { 2 - 8 } & DBAC & 10 & 3 & 1 & 1 & 1 & - \\
\hline & LBAC & 0.053 & 0.076 & 0.083 & 0.083 & 0.085 & 0.089 \\
\cline { 2 - 8 } & DBAC & 0.145 & 0.126 & 0.095 & 0.095 & 0 & - \\
\hline
\end{tabular}

Fig. 5. Cumulative survival curves of localized $\mathrm{BAC}(L B A C)$ and diffuse $\mathrm{BAC}(D B A C)(p=0.0002)$.pt., Patients; $S E$, standard error.

to $4.6 \%$ ). An increased incidence of BAC may result from improved recognition through better definition of the tumor.

It is well known that nodular BAC bears a better prognosis than infiltrative BAC. The roentgenographic appearance of BAC is closely related to the pathologic subtype of this tumor. Most of the nodular types of BAC are nonmucinous, and most of the infiltrative type are mucinous. The possible mechanism for different roentgenographic patterns and tumor spreading was well described by Ohori and colleagues $^{28}$ in 1992. In that study, BAC was divided into three subtypes: mucinous, nonmucinous, and sclerosing. The mucinous type tends to have high type IV collagen expression and low alpha- 2 integrin receptors, which predisposes the tumor cell to detach from the basement membrane. Aerogenous spreading is the consequence, and pulmonary infiltrate is the roentgenographic presentation. The sclerosing type shows increased type IV collagenase activity, which will destroy the basement membrane and will facilitate spread of the tumor through the lymphatic duct. We simplified our classification into localized BAC and diffuse BAC for evaluation of prognosis. Ten of our patients $(20 \%)$ had the diffuse type (bilateral or multiple pulmonary infiltrates). All of these patients had stage II disease or higher and only three patients $(30 \%)$ received resection. The median survival time was 4.3 months. On the contrary, 40 patients $(80.0 \%)$ had the localized type (pulmonary nodule or mass), of which $33(82.5 \%)$ underwent resection. The median survival time in this subtype was 27.5 months. Our data demonstrate that most localized BACs can be resected and that the survival is significantly higher than that of diffuse $\operatorname{BAC}(p=0.0002)$.

Daly and colleagues ${ }^{6}$ reported a $7.5 \%$ lymph node metastasis rate in BAC and concluded that BAC is more influenced by local neoplastic processes than by lymph node metastases. ${ }^{6}$ However, only 20 patients in this series had stage I disease. This was reflected by the $60 \%$ prevalence of lymph node or systemic metastasis at the time of diagnosis. Among the patients with stage I disease, six had stage T1 N0 M0 and 14 had stage T2 N0 M0 disease. The 5-year cumulative survivals for patients in these groups after curative resection were $83.3 \%$ and $25.7 \%$, respectively $(p=0.0961)$. The difference in survival times for these two groups was not significant, which may be related to a small sample size. Our experience shows that in the majority of patients the disease is diagnosed in the late stage and lymph node and systemic metastases are common findings.

As for the extent of surgical resection, one series 


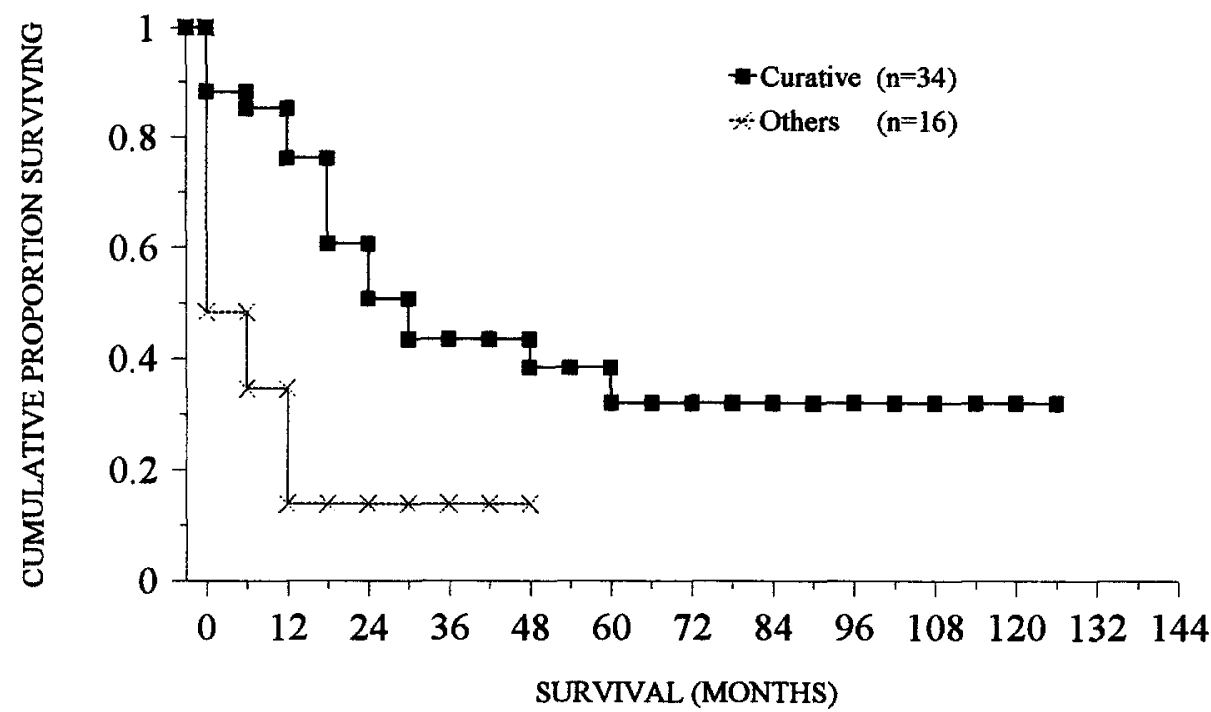

\begin{tabular}{|c|c|c|c|c|c|c|c|}
\cline { 2 - 8 } \multicolumn{1}{c|}{} & follow-up & 0 & $1 \mathrm{y}$ & $2 \mathrm{y}$ & $3 \mathrm{y}$ & $4 \mathrm{y}$ & $5 \mathrm{y}$ \\
\hline \multirow{3}{*}{ pt. at risk } & Curative & 34 & 28 & 19 & 11 & 9 & 6 \\
\cline { 2 - 8 } & Others & 16 & 5 & 1 & 1 & 1 & - \\
\hline \multirow{2}{*}{ SE } & Curative & 0.055 & 0.074 & 0.088 & 0.089 & 0.092 & 0.097 \\
\cline { 2 - 8 } & Others & 0.127 & 0.090 & 0.090 & 0.090 & 0 & - \\
\hline
\end{tabular}

Fig. 6. Cumulative survival curves according to type of resection $(p=0.0001)$.pt., Patients; $S E$, standard error.

Table IV. Distribution of operative type among different stages of $B A C$

\begin{tabular}{lccc} 
& \multicolumn{2}{c}{ Type of resection } & \\
\cline { 2 - 3 } Stage & Curative & Noncurative & Total \\
\hline I & 18 & 2 & 20 \\
II & 4 & 0 & 4 \\
IIIa & 11 & 0 & 11 \\
IIIb & 0 & 3 & 3 \\
IV & 1 & 11 & 12 \\
Total & 34 & 16 & 50 \\
\hline
\end{tabular}

showed no difference in survivals for wedge resection and lobectomy for $\mathrm{T} 1$ group BAC. However, in a comparison of the surgical results for stage I BAC from two recent large series, the 5-year survivals were quite different $(75.2 \%$ versus $55 \%){ }^{6,7}$ This discrepancy might be caused by understaging of the lung cancer in the series of Harpole and associates ${ }^{7}$ because of inadequate lymph node staging. One large series from Japan showed that only $54.9 \%$ of the T1 lung cancers were free from lymph node involvement. ${ }^{29}$ These findings further support routine mediastinal lymph node dissection in lung cancer operations.

In this series, 40 patients with stage I to stage IIIa disease underwent operation. Thirty-six patients $(90 \%)$ underwent tumor resection, and the majority
Table V. $p$ Values among different stages of BAC in the curative resection group

\begin{tabular}{cccc}
\hline & \multicolumn{3}{c}{ Stage } \\
\cline { 2 - 4 } & $I I$ & IIIa & $I V$ \\
\hline Stage & & & \\
I & 0.8075 & 0.1911 & 0.0983 \\
II & - & 0.2583 & 0.1573 \\
IIIa & - & - & 0.1624 \\
\hline
\end{tabular}

of the operations were considered as curative $(85 \%)$. All of the four unresectable cases of BAC involved clinical stage IIIa disease. Our resection rate was similar to that of previous reports. $6,7,30$ The median survival times in the groups with curative and noncurative resection were 30.6 months and 5.8 months, respectively $(p=0.0001)$. The results indicate that complete surgical resection provides the only chance for long-term survival.

In conclusion, our data showed the following: (1) the prevalence of BAC was steady during the observation period, (2) BAC presented at an earlier age in women, (3) lymphatic spread and systemic metastasis were common findings, (4) most cases of localized BAC were resectable, and (5) long-term survival correlated with initial roentgenographic appearance, TNM stage, and 
the completeness of surgical resection. The results indicate that most cases of BAC are diagnosed at a relatively late stage. However, if a curative surgical procedure can be done, a good chance for long-term survival still can be anticipated according to individualized TNM staging.

\section{REFERENCES}

1. Malassez L. Examen histologique d'un cas de cancer encéphaloïde du poumon (épithélioma). Arch Physiol Norm Pathol 1876;3:353-72.

2. Delarue NC, Graham EA. Alveolar cell carcinoma of the lung (pulmonary adenomatosis Jagziekte?). J Thorac Cardiovasc Surg 1949;18:237-51.

3. James EC, Schuchmann GF, Hall RV, Patterson JR, Gillespie JT, Gomez AC. Preferred surgical treatment for alveolar cell carcinoma. Ann Thorac Surg 1976; 22:157-62.

4. Greco RJ, Steiner RM, Goldman S, Cotler H, Patchefsky A, Cohn HE. Bronchoalveolar cell carcinoma of the lung. Ann Thorac Surg 1986;41:652-6.

5. Munnell ER, Dilling E, Grantham RN, Harkey MR, Mohr JA. Reappraisal of solitary bronchiolar (alveolar cell) carcinoma of the lung. Ann Thorac Surg 1978;25:289-97.

6. Daly RC, Trastek VF, Pairolero, et al. Bronchoalveolar carcinoma: factors affecting survival. Ann Thorac Surg 1991;51:368-77.

7. Harpole DH, Bigelow C, Young WG, Wolfe WG, Sabiston DC Jr. Alveolar cell carcinoma of the lung: a retrospective analysis of 205 patients. Ann Thorac Surg 1988;46:502-7.

8. Liebow AA. Bronchiolo-alveolar carcinoma. Adv Int Med 1960;10:329-58.

9. Berkman Y. The many faces of bronchoalveolar cell carcinoma. Semin Roentgenol 1977;12:207-14.

10. Hill CA. Bronchoalveolar cell carcinoma: a review. Radiology 1984;150:15-20.

11. Storey CF, Knudtson KP, Lawrence BJ. Bronchioloar (alveolar cell) carcinoma of the lung. J THORAC Cardiovasc Surg 1953;26:331-406.

12. Kaplan EL, Meier P. Nonparametric estimation from incomplete observations. J Am Stat Assoc 1958;53: 457-86.

13. Lee ET, Desu MM. A computer program for comparing $\mathrm{K}$ samples with right-censored data. Computer Programs in Biomedicine 1972;2:315-21.

14. Knudson RJ, Hatch HB, Mitchell WT, Ochsner A. Unusual cancer of the lung: II-bronchiolar carcinoma of the lung. Dis Chest 1965;48:628-33.

15. Ludington LG, Verska JJ, Howard T, Kypridakis G, Brewer LA III. Bronchiolar carcinoma (alveolar cell), another great imitator: a review of 41 cases. Chest 1972;61:622-8.

16. Duran-Reynals F, Jungher E, Cuba-Caparó A, Rafferty KA Jr, Helmboldt C. Pulmonary adenomatosis complex in sheep. Ann N Y Acad Sci 1958;70:72642.

17. Hod I, Herz A, Zimber A. Pulmonary carcinoma (Jaagsiekte) of the sheep: ultrastructural study of early and advanced tumor lesions. Am J Pathol 1977; 86:545-58.

18. Bonne C. Morphological resemblance of pulmonary adenomatosis (Jaagsiekte) in sheep and certain cases of cancer of the lung in man. Am J Cancer 1939;35: 491-501.

19. Nordquist RE. Specific antigens in human alveolar cell carcinoma. Cancer Res 1973;33:1790-5.

20. Mohr JA, Nordquist RE, Coalson RE, Rhoades ER, Coalson JJ. Lymphocyte-associated antigens in patients with alveolar cell carcinoma. J Lab Clin Med 1975;86:490-3.

21. Clayton F. The spectrum and significance of bronchioloalveolar carcinoma. Pathol Annu 1988;23:361-94.

22. Dermer GB. Origin of bronchioloalveolar carcinoma and peripheral bronchial adenocarcinoma. Cancer 1982;49:881-7.

23. Singh G, Katyal SL, Torikata C. Carcinoma of type II pneumocytes: PAS staining as a screening test for nuclear inclusion of surfactant specific apoprotein. Cancer 1982;50:946-8.

24. Kuhn C. Fine structure of bronchiolo-alveolar cell carcinoma. Cancer 1972;30:1107-18.

25. Paul SM, Bacharach M, Goepp C. A genetic influence on alveolar cell carcinoma. J Surg Oncol 1987;36:24952.

26. Merine D, Meziane M, Fishman EK, Hruban RH, Khouri N. Bronchioalveolar carcinoma: emphasis on localized lesions. South Med J 1989;82:475-80.

27. Huang ZY. Pathologic analysis of 302 primary bronchogenic adenocarcinomas. Chung Hua Chung Liu Tsa Chih 1988;10:280-3.

28. Ohori NP, Yousem SA, Griffin J, Stanis K. Comparison of extracellular matrix antigens in subtypes of bronchioloalveolar carcinoma and conventional pulmonary adenocarcinoma: an immunohistochemical study. Am J Surg Pathol 1992;16:675-86.

29. Naruke T. Significance of lymph node metastases in lung cancer. Semin Thorac Cardiovasc Surg 1993;5: 210-8.

30. Rossing TH, Rossing RG. Survival in lung cancer: analysis of the effects of age, sex, resectability, and histopathologic type. Am Rev Respir Dis 1982;126: 771-7. 